Part of Journal of Research of the National Bureau of Standards, Volume 30, June 1943

\title{
MEASUREMENTS OF ULTRAVIOLET SOLAR RADIATION IN WASHINGTON, 1936 TO 1942
}

\author{
By W. W. Coblentz and R. Stair
}

\section{ABSTRACT}

Continuing earlier measurements of ultraviolet solar radiation (RP877), a summary is given of similar measurements made during the years 1936 to 1942 , in Washington, D. C. Marked variations in the spectral quality and total intensity of ultraviolet solar radiation, attributable to variations in atmospheric turbidity, and, to a less extent, to well-known cyclonic and seasonal changes in ozone concentrations in the stratosphere, are recorded. On the clearest days the biologically effective ultraviolet of wavelengths shorter than $3132 \mathrm{~A}$, incident directly from the sun and the surrounding sky at midday, ranges from about 75 microwatts per square centimeter $\left(\mu \mathrm{w} / \mathrm{cm}^{2}\right)$ in midsummer to about $12 \mu \mathrm{w} / \mathrm{cm}^{2}$ in midwinter.

\section{CONTENTS}

Page

I. Introduction

II. Apparatus and methods

III. Discussion of ultraviolet solar intensity data_... 443

IV. References and notes _._.

\section{INTRODUCTION}

The evaluation of the biologically effective component of ultraviolet in sunlight is still in its infancy. The difficulties and uncertainties involved in present-day measurements of the ultraviolet component of sunlight are somewhat comparable with those experienced in the beginning of the evaluation of the total incident solar radiation of all wavelengths, half a century ago.

For some years the present writers have been engaged in an investigation of instruments and methods of evaluating the biologically effective component of ultraviolet solar and sky radiation useful in heliotherapy.

In a previous paper [1] ${ }^{1}$ measurements were given of the biologically effective ultraviolet solar radiation of wavelengths $3132 \mathrm{~A}$ and shorter, incident normally in Washington, during the years 1934 and 1935. The present paper summarizes similar measurements made on some of the clearest days during the years 1936 to 1942 , inclusive.

The hereindescribed measurements of ultraviolet solar intensities, incident normally upon the earth's surface, were obtained principally for three purposes:

(a) to secure data on the intensities, incident directly from the sun and from a small contiguous portion of the sky, that may be expected on relatively clear days at a sea-level station in midlatitude (which in-

1 Figures in brackets indicate the literature references and notes at the end of this paper. 
formation is of important in biological and photochemical irradiation experiments using a small exposure aperture);

(b) to secure data required in working out methods of evaluating the biologically effective component of ultraviolet solar radiation [1] - required particularly in one method of standardizing ultraviolet dosage-intensity meters $[4,11]$; and

(c) to determine whether, with the accuracy attainable in the radiometric measurements, the reduction factors $(F, G)$ used in the calculations of ultraviolet intensities, will require modifications with changes in the spectral quality of the biologically effective ultraviolet radiation, which varies with the ozone concentration in the stratosphere, which, in turn, varies with the latitude, the season, the barometric pressure (movements of masses of polar air) and, less systematically, with the sunspot cycle $[5,6,18]$.

\section{APPARATUS AND METHODS}

In previous publications, descriptions were given of the instruments used in making ultraviolet solar-intensity measurements and the methods of evaluating the biologically effective spectral component of wavelengths $3132 \mathrm{~A}$ and shorter $[1,2,7]$. It will therefore suffice to recall that the intensity measurements were made with a spectrally selective radiometer [2] consisting of Ti-photoelectric cells sensitive to wavelengths $3500 \mathrm{~A}$ and shorter, and suitable glass filters that exclude ultraviolet radiation of wavelengths $3150 \mathrm{~A}$ and shorter.

The photoelectric cell in its mounting is shown in figure 1 of reference [7]. The aperture exposed to the sun and surrounding sky is about $22^{\circ}$. As shown in previous papers, at high elevations the amount of ultraviolet sky radiation is small (p. 142 of ref. [7]). On the other hand, a: a sea-level station even a slightly hazy atmosphere greatly increases the amount of ultraviolet sky radiation; but the total ultraviolet radiation from the sun and from a small part of the surrounding sky, incident normal upon the photocell receiver, is greatly reduced-see the measurements of April 13 and 16, 1942, depicted in figure 10.

Using a photoelectric cell and filter method [1,2], the separation of the amount of biologically effective ultraviolet solar radiation of wavelengths $3132 \mathrm{~A}$ and shorter from the total amount of all wavelengths measured by a particular photoelectric cell (having a threshold of response at 3200 to $3500 \mathrm{~A}$ ), requires measurements of the total intensity of the radiation to which the photoelectric cell responds and the amount transmitted through the filters at various solar altitudes. A knowledge is required also of: (a) the spectral response of the photoelectric cell, (b) the ultraviolet spectral transmissions of the filters, (c) the ultraviolet spectral-energy distribution at different solar heights (air masses), and (d) calibration of the ultraviolet meter, in absolute value, against a standard of ultraviolet radiation [8].

At the beginning of these investigations [20], based upon the spectral range of the erythemic and antirachitic responses, the intense emission line in the mercury arc at $3132 \mathrm{~A}$ was adopted as the long-wavelength limit of biological effectiveness. In the meantime, it has been established that the spectral range of the tanning reaction extends to longer wavelengths [9], upon which basis it seemed logical to place the limit of biological effectiveness at $3200 \mathrm{~A}$ [10]. Another reason for considering the adoption of a threshold of biological effectiveness at longer wavelengths was the development of photocells sensitive 
only to wavelengths shorter than about $3200 \mathrm{~A}$, for use in measuring solar and sky radiation on a horizontal plane [11]. If reproducible photoelectric cells with the same threshold of response were available, ultraviolet radiometry would be greatly simplified. Thus far, however, it has been impossible to make photocells having the same threshold of response. Hence, in view of the well-established use of $3132 \mathrm{~A}$ in specifying the long-wavelength limit of biological effectiveness, it seems desirable to continue the use of this wavelength limit. This, of course, requires the continuation of the use of complicated factors for reducing the measurements obtained with various photoelectric cells and filters. In the present paper (figs. 4 to 9 , inclusive) the data are given for both spectral ranges-to $3132 \mathrm{~A}$ and to $3200 \mathrm{~A}$, respectively.

The procedure employed in calculating the factor $P$, used in calibrating the photoelectric cell against a primary standard of ultraviolet radiation, and the factor $G$, used in evaluating the ultraviolet solar radiation of wavelengths shorter than $3132 \mathrm{~A}$ (or $3200 \mathrm{~A}$ ) relative

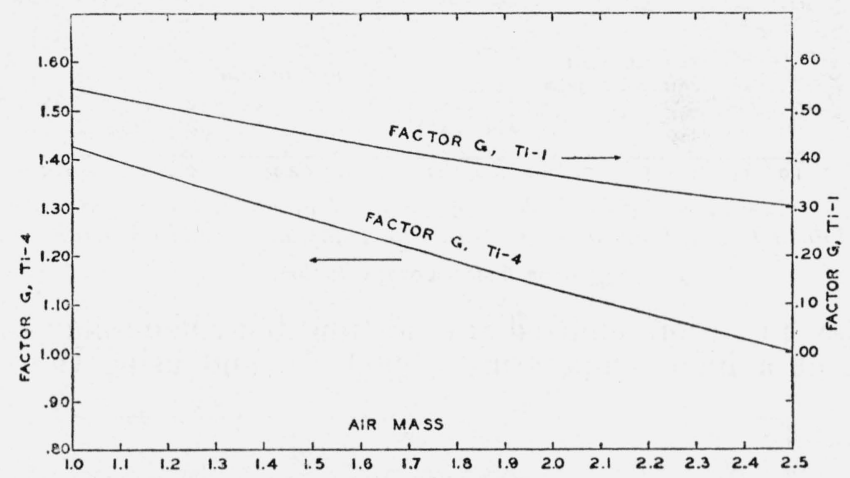

FIGURE 1.-Reduction factors, $G$, used in determining the amount of ultraviolet solar radiation of wavelengths shorter than and including $3200 A$ relative to the total spectral range measured with photoelectric cells Ti-1 and Ti-4.

to the total range of wavelengths to which the photocell responds, is described in previous papers $[1,13]$. As a matter of record, in figure 1 are illustrated the reduction factors $G$ for the spectral band of $3200 \mathrm{~A}$ and shorter wavelengths for comparison with figure 5 of reference [1] for the band of $3132 \mathrm{~A}$ and shorter wavelengths. Obviously, if photocells can be developed having the same threshold response (say 3200 A) for use as comparison standards, the same factor $G$ can be used for all or be eliminated entirely by comparison with primary standards.

The weak point in the calculation of the factor $G$ is the lack of exact knowledge of the spectral distribution of energy in the extreme ultraviolet of solar radiation at the observing station. The method of deducing the solar spectral-energy distribution by means of various photoelectric cells and filters is described in previous publications ([7] and p. 323 of ref. [1]). To simplify the calculations, a smooth spectral-energy distribution is assumed, although from the very beginning [20] it was noted that the energy curve is deeply indented (see fig. 2 of ref. [7] and p. 167 of RP1367 [18]) by numerous Fraunhofer and ozone absorption lines. 
This method of checking the ultraviolet spectral-energy distribution may be criticized because of the difficulty in determining the threshold and the shape of the spectral photoelectric response. The recent determinations of the spectral responses of our photoelectric cells, using a monochromator and a mercury- or cadmium-arc lamp, are therefore supplemented by integrated filter-transmission measurements of the

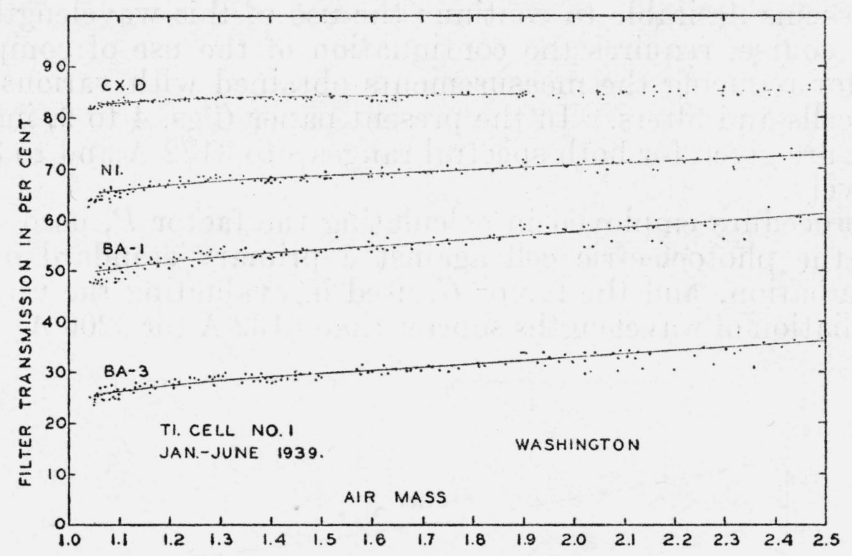

Figure 2.-Diurnal variation in transmission of ultraviolet solar radiation through standard filters, from January to June 1989, observed in Washington.

See fig. 3 for seasonal variation.

ultraviolet radiation emitted by a tungsten-ribbon-filament lamp operated at a high temperature $\left(2,900^{\circ} \mathrm{K}\right)$, and using the spectral-

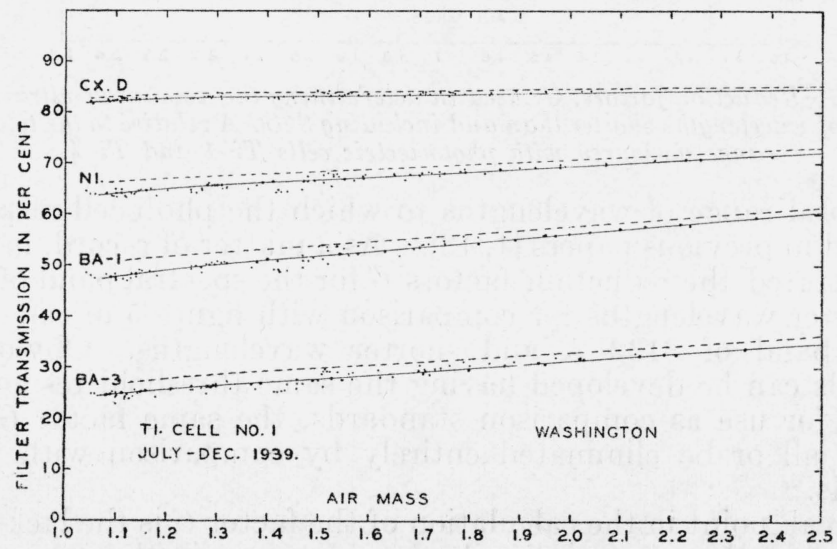

FIGURE 3.-Diurnal and (dotted curves from fig. 2) seasonal variation in transmission of ultraviolet solar radiation through standard filters, observed from July to December 1939, in Washington, D. C.

energy data observed by Hamaker [14] (communicated by Ornstein [14]) and by Hoffmann and Willenberg [15].

As shown elsewhere [16, 17], based upon integrated ultraviolettransmission measurements made with four filters of known spectral ultraviolet transmissions and eight photoelectric cells differing widely 
in spectral photoelectric response, the average values of the spectral emissivities of tungsten, in the band of wavelengths extending from 2,400 to 3,500 A, observed by Hoffmann and Willenberg appear to be substantially correct. Hence, as mentioned above, in recent determinations of the spectral response of a photoelectric cell, the wide gaps between the response measurements, made with the spectrally isolated emission lines of the mercury and the cadmium arc (at 3,024, 3,132, $3,261,3,342$, and $3,663 \mathrm{~A}$ ) are filled in on the basis of a smooth spectral photoelectric response curve that is adjusted to give calculated filter transmissions in agreement with the integrated filter transmissions observed on the ultraviolet radiation from a tungsten-ribbon lamp operated at a known temperature.

From our most recent studies it appears that the ultraviolet solar spectral-energy distributions, published in table 2 (p. 323 of ref. [1]), remain unchanged for air masses $m=2$, and less; but for air masses, $m=2.3$ and larger, the data appear to belong to air masses about 0.3 larger, e. g., $m=3.3$ instead of $m=3.0$. However, for these large air masses the spectral intensities of the shortest wavelengths are so small that this uncertainty seems relatively negligible in the present-day stage of evaluation of biologically effective ultraviolet solar radiation. As noted in earlier papers $[1,12]$, the good agreement in the measurements of the biologically effective component of ultraviolet solar radiation of wavelengths shorter than $3,132 \mathrm{~A}$, obtained with spectrally nonselective thermopiles and with wavelength-selective radiometers differing greatly in range of spectral photoelectric response, appears to be real and not the result of a fortuitous combination of factors, including (a) the spectral responses of the photoelectric cells, (b) the spectral transmissions of the filters, and (c) the transmissions of the integrated ultraviolet solar radiation through the various filters.

In figures 4 to 10 , inclusive, the ultraviolet intensities are given in the two above-mentioned spectral ranges, extending from the shortest incident wave lengths (at about $2900 \mathrm{~A}$ ) to $3132 \mathrm{~A}$ and to $3200 \mathrm{~A}$, respectively. The values of the intensities in these two spectral ranges differ by about 40 percent, varying from about 33 percent for air mass, $m=3$, to about 48 percent for $m=1.05$. In these illustrations the scale on the right-hand side is to the nearest rounded numbers. Based upon some preliminary trials [4], it is believed that when satisfactory photoelectric cells are obtainable for use as primary standards, the calibration of meters for measuring ultraviolet solar and sky radiation incident on a horizontal plane will be greatly simplified.

During the 7 years of measurements included in the present report, two of the filters ( $\mathrm{Ba}-1$ and $\mathrm{Ba}-3$, a soft glass) became slightly scratched from frequent wiping with a fine-haired brush and were replaced by others of practically the same thickness. No difference was observed in the ultraviolet intensities deduced from the measurements with the old and new filters. Furthermore, frequent calibration against a primary standard of ultraviolet radiation showed no systematic change in the sensitivity of the photocells (Ti-1 and Ti-4, illustrated in figs. 1 and 2 of ref. [7]) used throughout these researches. From this it appears that the instrumental precision from year to year was maintained within 10 percent, or even closer. 
The accuracy attained in the measurements of ultraviolet solar intensities was limited entirely by meteorological conditions. As

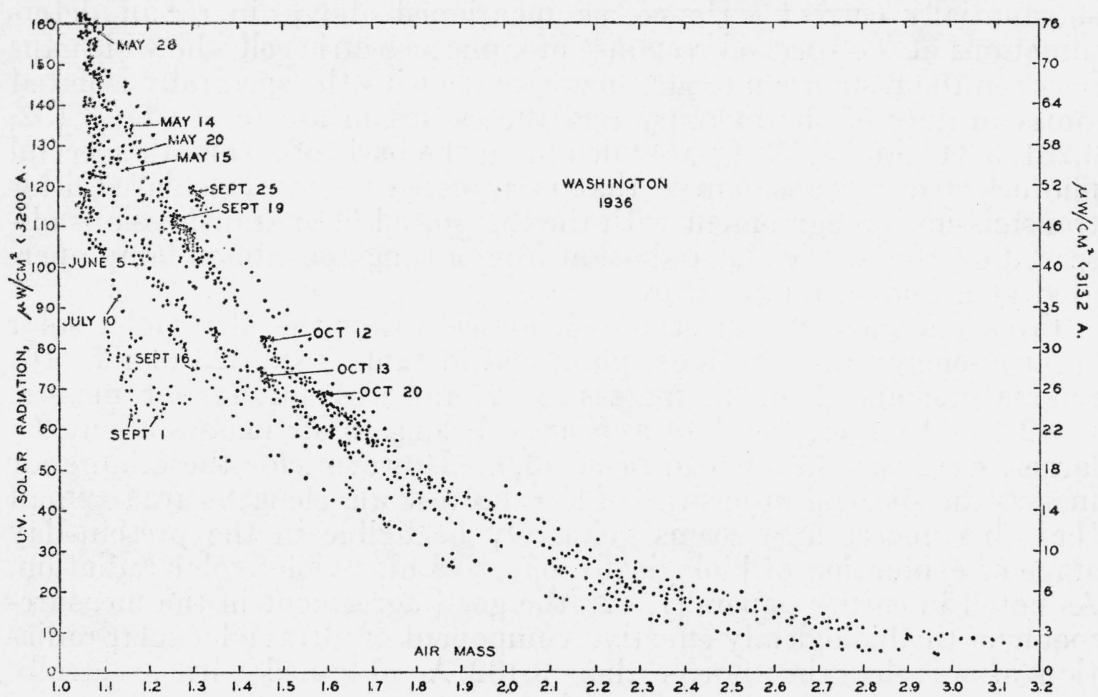

FIGURE 4.-Measurements of ultraviolet solar radiation of wavelengths shorter than 3192 A, also $3200 A$ and shorter, during some of the clearest days in 1936 .

noted in previous papers, on the clearest days at high elevations (Flagstaff, Ariz.) where the measurements could be repeated to 0.1 to 0.2 percent, a change in spectral quality and total intensity, result-

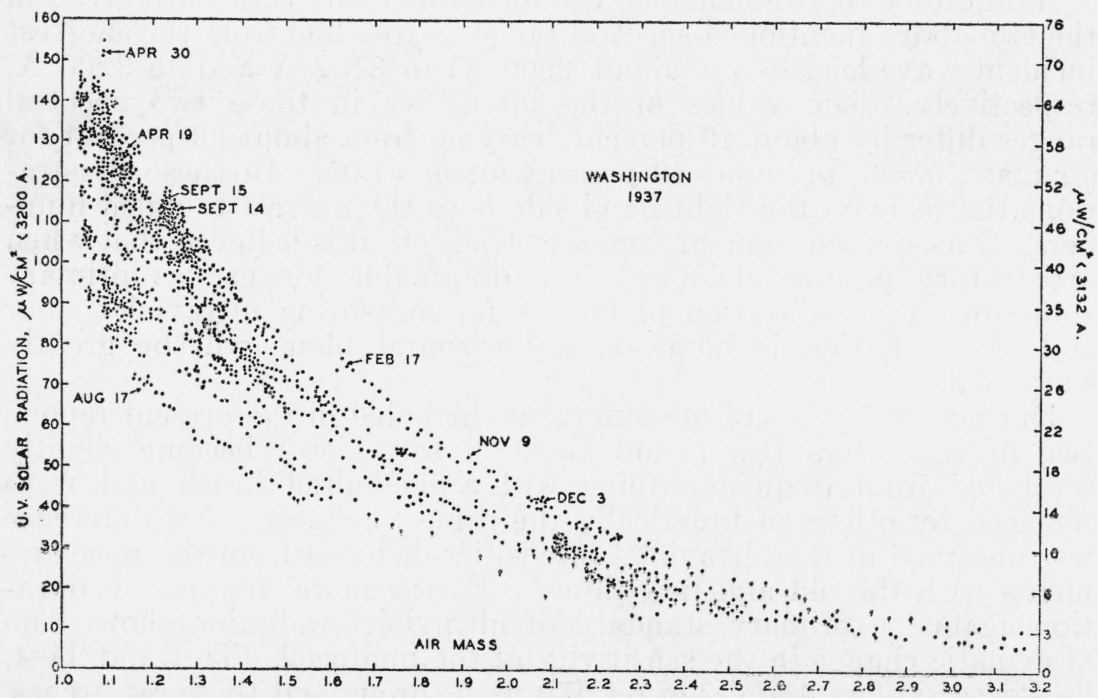

FIGURE 5.-Measurements of ultraviolet solar radiation of wavelengths shorter than $3132 \mathrm{~A}$, also $3200 \mathrm{~A}$ and shorter, during some of the clearest days in $193 \%$.

ing from a change in solar height, was observed from minute to minute. 
In contrast, at sea-level stations (San Juan, P. R., and Washington, D. C.) with a continual variation in turbidity in the lower atmos-

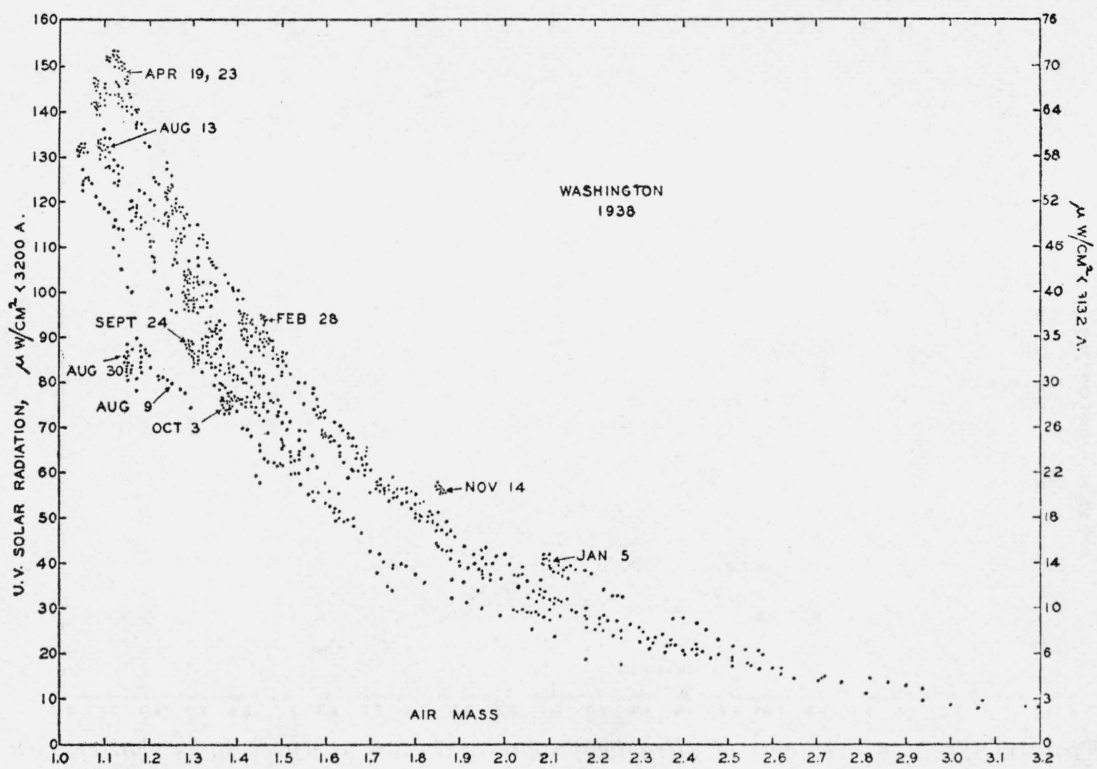

FIGURE 6.-Measurements of ultraviolet solar radiation of wavelengths shorter than 3132 A, also $3200 A$ and shorter, during some of the clearest days in 1938.

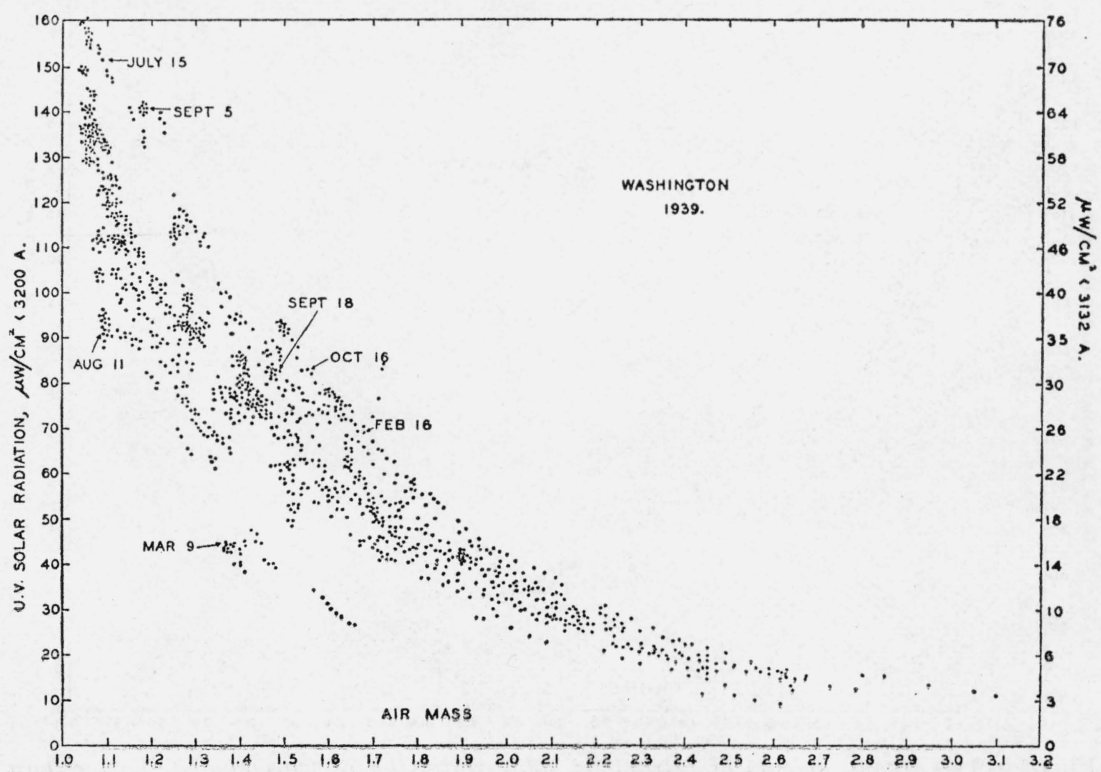

FIG URE 7.-Measurements of ultraviolet solar radiation of wavelengths shorter than $3132 \mathrm{~A}$, also $3200 \mathrm{~A}$ and shorter, during some of the clearest days in 1939.

phere, the precision attained is best shown graphically in the measurements of April 13 and 16, 1942, figure 10, where each measurement (the 
instantaneous value in the group, say at $m=1.2$ and at $m=1.3)$ is probably accurate to 1 percent. Nevertheless, because of atmos-

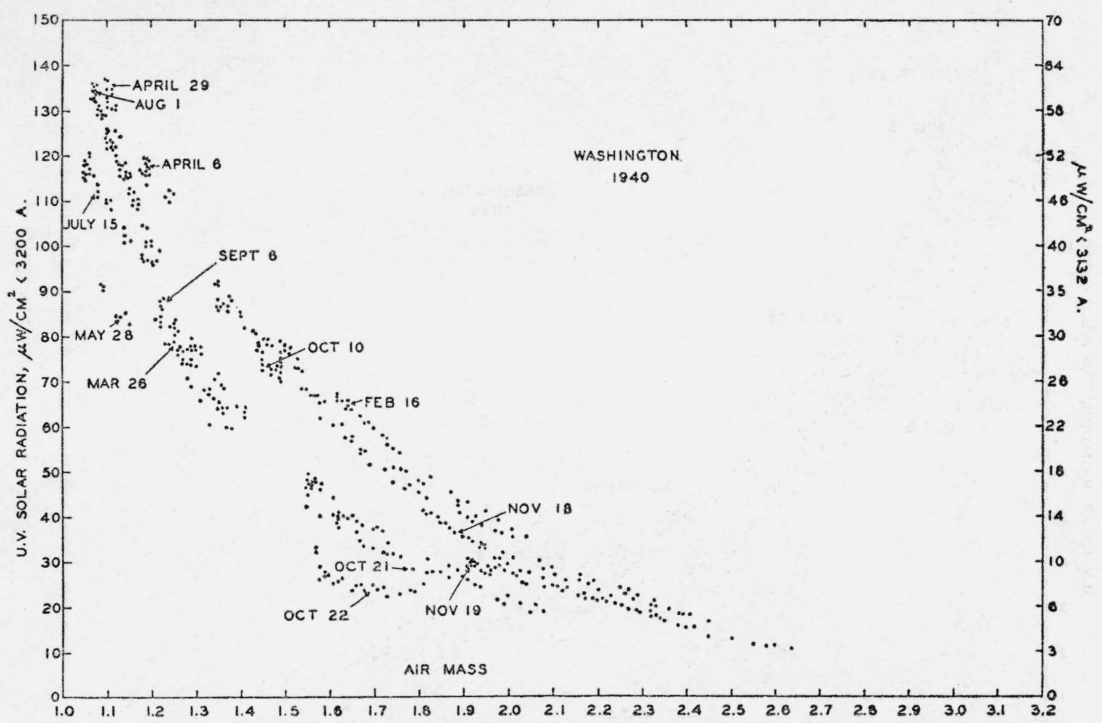

FigURE 8.-Measurements of ultraviolet solar radiation of wavelengths shorter than 3132 A, also 3200 A and shorter, during some of the clearest days in 1940.

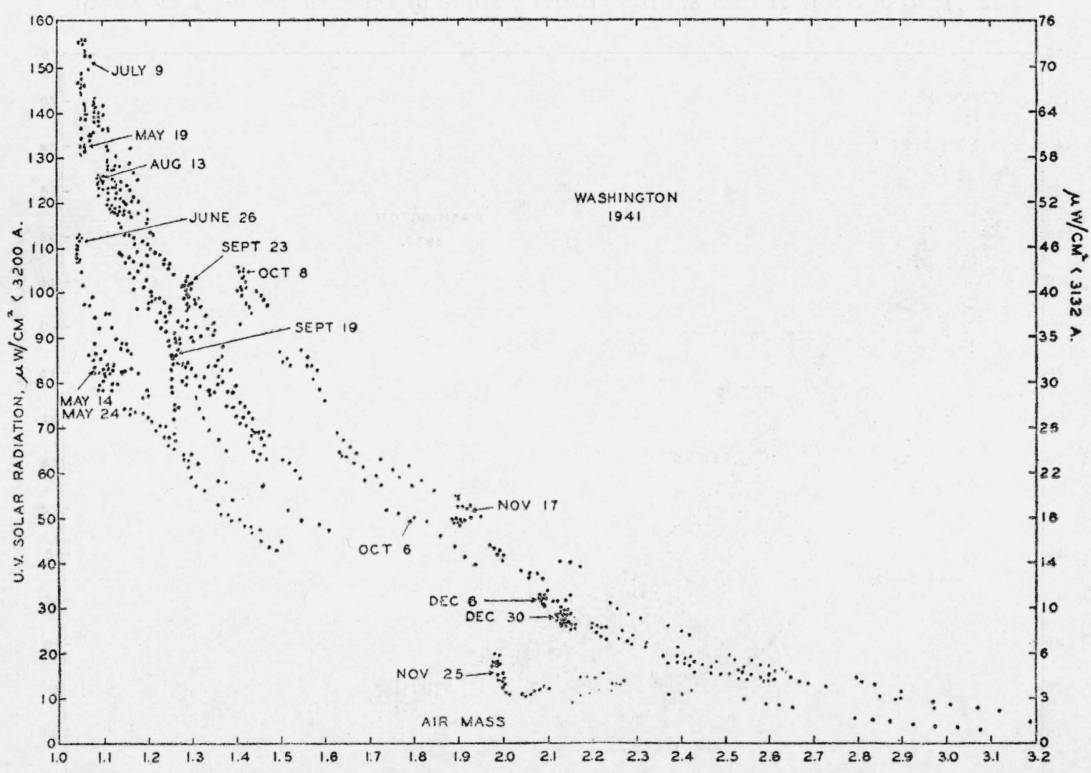

FIGURE 9.-Measurements of ultrai iolet solar radiation of wavelengths shorter than 3132 A, also 3200 A and shorter, during some of the clearest days in 1941.

pheric conditions the average values for these two days are best represented by the two lines drawn through these measurements. 
The wide spread in the values of the ultraviolet solar intensities depicted in figures 4 to 10 , inclusive, is attributable to constantly varying meteorological conditions. This was shown in an earlier paper (fig. 6 of ref [1], where a detailed description is given of the effect of a slight change in turbidity upon the ultraviolet intensities observed throughout an exceptionally clear day, May 18, 1935.

The accuracy attained in the absolute values of the herein-described measurements of ultraviolet solar intensities is somewhat of a conjecture. As noted in a previous paper (p. 335 and fig. 6 of ref. [1]), using three distinctly different methods of evaluation (thermoelectric

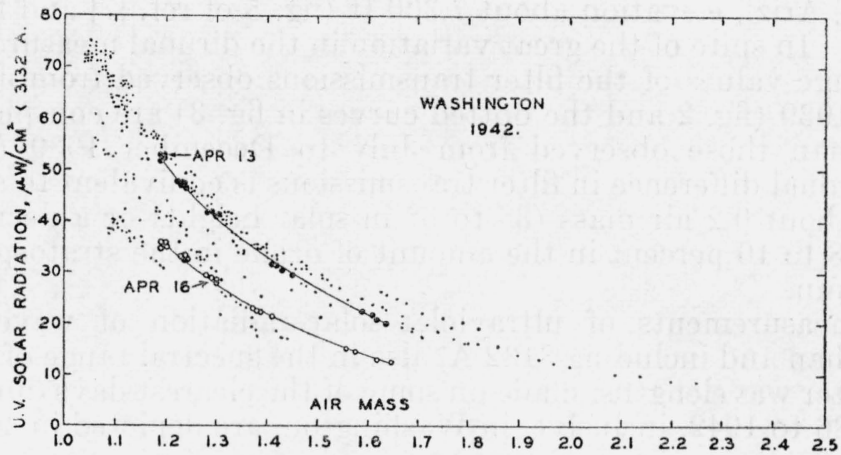

FIGURE 10.-Measurements of ultraiciolet solar radiation of wavelengths shorter than 3132 A, dr ring some of the clearest days in 1942.

The large black dots, and the circles, connected with lines, indicate measurements on 2 days, differing greatly in atmospheric turbidity.

and photoelectric), the ultraviolet solar intensities, of wavelengths $3132 \mathrm{~A}$ and shorter, observed at midday in Washington during the clearest midsummer weather, range from 75 to $78 \mu \mathrm{w} / \mathrm{cm}^{2}$.

Using measured intensities of ultraviolet solar radiation, from erythematogenic tests made at two sea-level stations (San Juan, P. R., and Washington, D. C.) and at two high elevations (7,300 and 10,000 ft.; Flagstaff and the San Francisco Peaks, Ariz.), the uncertainty in the radiometric evaluation seems to be no greater than the uncertainty in the biological evaluation used in checking the radiometric measurements, viz., 10 to 15 percent [1]. This uncertainty is due to a lack of knowledge of the spectral-energy distribution of solar radiation in the biologically effective range of wavelengths $3200 \mathrm{~A}$ and shorter. Similar radiometric and biologic comparisons made by Greider and Downs, by Luckiesh, and by Pettit (discussed on p. 973 of ref. [20], reduced to the same range of wavelengths, are in good agreement with the foregoing data.

\section{DISCUSSION OF ULTRAVIOLET SOLAR INTENSITY DATA}

In previous papers it was shown that, for the same solar altitudes, the atmosphere is more transparent to ultraviolet radiation of short wavelengths in the afternoon than in the forenoon and more transparent in the autumn than in the spring (p. 144 and fig. 5 of ref. [7]). The reason therefor is the presence of less ozone in the stratosphere in 


\section{Journal of Research of the National Bureau of Standards}

the autumn than in the spring $[5,6]$, and presumably less in the afternoon than in the forenoon. While, in the present stage of evaluation of ultraviolet solar radiation, this difference in atmospheric transparency is not taken into consideration (see figs. 2 and 5 of ref. [1]), it is evident that, at stations where atmospheric conditions are sufficiently constant to warrant such refinements in reducing the observations, this variation in ultraviolet transparency should be included in the calculations.

In figure 2 of a previous publication [1] a sudden, presumably seasonal, change in atmospheric transparency was observed in the tropics. Similar changes are evident from the filter measurements made at Flagstaff, Ariz., elevation about 7,300 ft (fig. 5 of ref. [7] and fig. 3 of ref. [18]). In spite of the great variation in the dirunal measurements, the average values of the filter transmissions observed from January to June 1939 (fig. 2 and the dotted curves in fig. 3) are conspicuously higher than those observed from July to December 1939 (fig. 3). This seasonal difference in filter transmissions is equivalent to a difference of about 0.2 air mass $\left(3^{\circ}\right.$ to $5^{\circ}$ in solar height) or a decrease of perhaps 8 to 10 percent in the amount of ozone in the stratosphere in the autumn.

The measurements of ultraviolet solar radiation of wavelengths shorter than and including $3132 \mathrm{~A}$, also in the spectral range of $3200 \mathrm{~A}$ and shorter wavelengths, made on some of the clearest days during the years 1936 to 1942, inclusive, in Washington, are depicted in figures 4 to 10 .

The wide difference in the ultraviolet intensities observed from day to day at any given solar height (air mass in these illustrations) is attributed primarily to variations in atmospheric turbidity, although changes in the amount of ozone in the stratosphre also cause variations in ultraviolet intensities. Even a slight increase in atmospheric scattering (as judged by the solar corona) greatly decreases the intensity of ultraviolet radiation incident on a surface exposed normal to the sun's rays. This was repeatedly observed in the measurements of 1942 (fig. 10), the most of which were made in connection with the calibration of a photoelectric cell used for measuring ultraviolet solar and sky radiation incident on a horizontal plane $(4,11]$. In the course of these measurements of solar and sky radiation it was repeatedly observed (by shadowing the receiver from the direct solar rays) that it was only during the noon hours of the clearest days in early summer that the ultraviolet radiation from the whole sky incident on a horizontal surface was slightly less than the directly incident solar rays, and that when the sky was slightly turbid, the ultraviolet radiation from the whole sky was at least 2.5 times greater than the directly incident solar rays [3, 4].

A specific example of the decrease in intensity caused by atmospheric scattering is illustrated in the measurements of April 13 and 16, 1942, depicted in figure 10. On April 13 (sky blue; no corona) the ratio of the ultraviolet in sky radiation to direct solar radiation was 1:1. On April 16 (sky turbid; white corona) the ultraviolet sky radiation was 2.5 times greater than the direct solar radiation. In this instance, however, contrary to general experience, the filter transmissions were lower on April 16 than on April 13, indicating the presence of a relatively greater amount of ultraviolet of the shortest wavelengths on April 16. This might be due to selective atmospheric (Rayleigh) 
scattering (see p. 146, of ref. [7]). On the other hand, the barometer was higher (760 $\mathrm{mm}$ for 2 days; hence, there probably was less ozone) on April 16 than on April 13, when the barometer (759 mm) was rising from a (cyclonic) barometric low that occurred on April 10 to 11 . It is therefore probable that on April 16 the reduction in ultraviolet intensities by atmospheric scattering was compensated for appreciably by an increased transparency (caused by a decreased ozone content) of the stratosphere to ultraviolet solar radiation. In this connection, reference is made to measurements procured at high altitudes (Flagstaff, Ariz., elevation 7,300 ft) showing the effect of (a) scattering by atmospheric water vapor and (b) variation in barometric pressure, and an accompanying variation in ozone content of the stratosphere, upon the incident ultraviolet solar radiation (see figs. 1 to 5 , inclusive, of ref. [18]).

With constantly changing atmospheric pollution and cloudiness, especially at sea-level stations, great variations in ultraviolet intensities may be expected. Hence, the measurements depicted in figures 4 to 10 represent only what may be expected under the most favorable atmospheric conditions.

As already mentioned, because of the seasonal decrease in ozone content and, hence, increase in transparency of the stratosphere, the ultraviolet intensities should be systematically higher in the autumn than for similar solar heights at other seasons. This is shown in figure 4 (Sept. 25, Oct. 20), figure 5 (Nov. 9, Dec. 3), figure 7 (Sept. 5 , Oct. 16), figure 9 (Oct. 8, Nov. 17), etc. However, while high ultraviolet solar intensities seem to predominate in the autumn, they occur frequently in the late winter and early spring (e. g., February and April; figs. 5, 6, 7, and 8), when the highest concentration of ozone usually prevails in the stratosphere (see fig. 1 of ref. [4]). Correcting for solar distance, the ultraviolet intensities in March, relative to September, would be reduced by about 2 percent. Evidently this does not explain the high ultraviolet solar intensities in February, which, more logically, are explainable on the basis of a temporary reduction in the ozone content (the "ozone holes" observed by Kiepenbeuer [19]) and a concomitant increase in transparency of the stratosphere to ultraviolet radiation of very short wavelengths [19].

These measurements were begun when the relative numbers of sunspots were low (minimum in 1934). They include the maximum of the sunspot cycle (April 1937; secondary maximum January 1939) and the period of rapidly decreasing sunspot numbers in 1941 and 1942 - predicated minimum about 1944.

The clearest weather is usually associated with a high or average barometric pressure. It is therefore rare to secure ultraviolet solarintensity measurements during a cyclonic disturbance, when atmospheric ozone is higher than normal (see fig. 5 and discussion on p. 575 to 577 of ref. [18].

The seasonal variation in atmospheric ozone, especially in midlatitude (see fig. 1 of ref. [4]), also must be considered. Since the time of making the hereindescribed measurements, from season to season, could not be selected (for example, there were but few clear days during the summer of 1940 - see fig. $8, m=1.05$ ) only generalized comparisons can be made. It therefore seems illusory to attempt to seek a correlation of these data with the sunspot cycle. For example, in the measurements of 1938 (fig. 6) the noon-hour ultraviolet inten- 
sities (u.v.Q.) for $m=1.1$ are higher than for $m=1.05$. This was owing to clearer weather in April than in June, and not because of the effect of sunspots upon the ultraviolet intensity. Selecting 2 years having the same sunspot numbers, in 1936 the U.v.Q. for $m=1.05$ is higher than in 1941; but in September the intensities are the same as, or they are higher than, observed during some other years. Again, in comparison with 1941, the u.v.Q. values of 1937 are low in April and September; and they are practically the same in February, November, and December.

In the absence of factors for eliminating the effect of atmospheric turbidity and the variability (seasonal and meteorological) of atmospheric ozone, it is impracticable to determine from these data the effect of sunspots upon the amount of ultraviolet emitted. In the few instances when observations could be made near the time when the ionosphere (and radio transmission) was disturbed by large outbursts of sunspots, the ultraviolet intensities showed nothing conspicuously different from the usual values.

The measurements depicted in figures 4 to 10 indicate what intensities may be expected in irradiation experiments using biological effective ultraviolet radiation incident from the sun and from a narrow portion of the surrounding sky, practically free from pollution by smoke, on relatively cloud-free days, at a practically sea-level station, Washington, D. C. The great variations in intensities from day to day, for the same solar height (air mass, in these illustrations), is caused primarily by differences in atmospheric turbidity. A specific example is illustrated in figure 10; April 13 and 16,1942, described on a preceding page. At the same solar height (air mass traversed) the intensity differs by 30 to 35 percent, primarily because of atmospheric scattering. As will be shown in a subsequent paper, the total incident ultraviolet solar and sky radiation, integrated for the whole day, was 16 percent less on April 16 when the sky was more turbid.

In figures 4 to 10 , inclusive, the dates attached to the low intensities indicate days that were conspicuously hazy; with no attempt at correlating the low values with atmospheric scattering and with increased ozone in the atmosphere as indicated by a decrease in barometric pressure.

From the data depicted in figures 4 to 10 , inclusive, it appears that at a sea-level station in midlatitude, on exceptionally clear days, the noon-hour intensity of biologically effective ultraviolet radiation of wavelengths less than $3132 \AA$, incident directly from the sun and a small portion of the surrounding sky, varies from about $75 \mu \mathrm{w} / \mathrm{cm}^{2}$ in June (air mass, $m=1.05$ ) to about $12 \mu \mathrm{w} / \mathrm{cm}^{2}$ in December $(m=$ 2.1). For similar measurements, made during 1934 and 1935, with noon-hour designations of intensities for all the months, reference is made to figure 7 of ref. [1].

In a previous paper (fig. 6 of ref. [4]) data were given showing that, in high latitudes $\left(78^{\circ} \mathrm{N}\right)$ at the noon-hour on the clearest days in midsummer, the intensity of the biologically effective ultraviolet radiation of wavelengths shorter than $3200 \mathrm{~A}$ from the sun and the whole sky, incident on a horizontal plane, ranged from 30 to $40 \mu \mathrm{w} / \mathrm{cm}^{2}$. As shown in the figures 4 to 10 of the present paper for the band of wavelengths shorter than $3132 \mathrm{~A}$, the corresponding values range from 10 to $14 \mu \mathrm{w} / \mathrm{cm}^{2}$. The longer spectral range includes more of the ultra- 
violet rays that produce tanning. The shorter spectral range is of more significance in the prevention of rickets.

As noted in the previous paper [4], the intensity and biological effectiveness of ultraviolet solar and sky radiation, in midsummer, in high latitudes $\left(78^{\circ} \mathrm{N}\right)$ is not markedly different from that observed at the same solar height in December $(m=2.1)$ in Washington. It was shown also that while these intensities are low, if long exposures can be made, they are effective in heliotherapy.

\section{REFERENCES AND NOTES}

[1] W. W. Coblentz and R. Stair, Evaluation of ultraviolet solar radiation of short wave lengths, J. Research NBS 16, 315 (1936) RP877. See p. 339 for accuracy attained in erythema tests.

[2] W. W. Coblentz and R. Stair, A portable ultraviolet meter, consisting of a balanced amplifier, photoelectric cell, and microammeter, BS J. Research 12, 231 (1934) RP647.

[3] Instruments and methods of radiometry, NBS Tech. News Bul. No. 289, p. 41 (May 1941). Reference to the use of an automatic inpulse ("traffic") counter in recording ultraviolet intensities [4].

[4] W. W. Coblentz, F. R. Gracely, and R. Stair, Measurements of ultraviolet solar and sky radiation intencities in high latitudes, J. Research NBS 28, 581 (1942) RP1469.

[5] G. M. B. Dobson, Measurements of the amount of ozone in the earth's atmosphere and its relation to other geophysical conditions, pt. IV, Proc. Roy. Soc. (London) [A] 129, 411 (1930). Appendix I, by H. H. Kimball, p. 418; appendix II, by E. Kidson, p. 421.

[6] F. W. P. Götz, Zum Strahlungsklima des Spitzbergensommers, Gerlands Beitr. Geophys. 31, 119 (1931).

[7] W. W. Coblentz and R. Stair, Factors affecting ultraviolet solar-radiation intensities, J. Research NBS 15, 123 (1935) RP816. See p. 142 for erythema tests, and figure 2 for photograph of the ultraviolet solar spectrum.

[8] W. W. Coblentz and R. Stair, A standard source of ultraviolet radiation for calibrating photoelectric dosage intensity meters, J. Research NBS 16, 83 (1936) RP858.

[9] M. Luckiesh and A. H. Taylor, Production of erythema and tan by ultraviolet energy, J. Am. Med. Assn. 112, 2510 (1939); İ. Hausser, Strahlentherapie 62, 315 (1938).

[10] W. W. Coblentz, The spectral range of ultraviolet solar radiation useful in climatology, Bul. Am. Meteorol. Soc. 22, 316 (1941).

[11] W. W. Coblentz and R. J. Cashman, A photoelectric cell for measuring ultraviolet solar and sky radiation on a horizontal plane, Bul. Am. Meteorol. Soc. 21, 149 (1940).

[12] W. W. Coblentz and R. Stair, Distribution of the energy in the extreme ultraviolet of the solar spectrum, J. Research NPS 1\%, 1 (1936) RP899.

[13] R. Stair and W. W. Coblentz, Radiometric measurements of ultraviolet solar intensities in the stratosphere, J. Research NBS 20, 185 (1938) RP1075.

[14] H. C. Hamaker, Reflectivity and Emissivity of Tungsten. Inaug. Diss., Utrecht, Holland (1934). L. S. Ornstein, Physika 3, 561 (1936).

[15] F. Hofiman and H. Willenberg, Ultraviolet emissivity of tungsten at high temperatures, Physik. Z. 35, 1 and 711 (1934).

[16] R. Stair and W. W. Coblentz, Spectral energy distribution of the standard comparison lamp used in evaluating the flash spectrum of the solar eclipse of 1940, Nat. Geographic Soc., Contrib. Tech. Papers, Solar Eclipse Series No. 2, 48 (1942).

[17] W. W. Coblentz, The emissivity and energy distribution of tungsten in the photographic region of the spectrum, Pub. Am. Astronom. Soc. 10, 222 (1942).

[18] W. W. Coblentz and R. Stair, Distribution of ozone in the stratosphere, J. Research NBS 22, 573 (1939) RP1207; 26, 161 (1941) RP1367.

[19] Ozone clouds and holes in the stratosphere: K. O. Kiepenheuer, Z. Astrophysik 14, 348 (1937); F. W. P. Götz, Helv. Phys. Acta 13, 3 (1940).

[20] W. W. Coblentz and R. Stai,, Measurements of extreme ultraviolet solar radiation by a filter method, BS J. Research 6, 951 (1931) RP318.

Washington, January 8, 1943. 